\title{
Thinking About Our Language
}

\author{
James Boyd White†
}

Except for one meeting, which I will describe below, I knew Bob Cover only through his writings. This circumstance was of course a disappointment to me, for our interests were similar, and his death now makes the loss irreparable. But perhaps this is less of a limitation than would normally be the case, for as much as any one in the law Bob was, and is, actively present in his writing, both as a person and as a mind.-But that dichotomy of person and mind gets it wrong, for what I would like to catch is a sense of fusion or integration: of intellect and passion, sympathy and objectivity, politics and thought, all suffused with the sense that law has meaning, whether we like it or not, and meaning at many different levels-for the slave, or master, or other victim of the law, for the judge torn apart by the injustice of the laws he is sworn to apply, for the student and professor and community whose lives are so largely defined by the law they have not made. But the meanings of the law do not just lie inertly out there in the world. They must be actively created and sustained, for the most part by the people of the law, who live in the great paradox of human life that implicates us all in the systems of belief and action we seek to criticize and change. Bob Cover's great gift was for seeing law not simply as a set of rules, nor as an instrument for social con-

trol, nor as the expression of policy, but as a system of meaning in its own right. In this he spoke to those of use who are drawn to the law as a life not merely of power but of significance.

The only occasion I spent time with Bob was at a conference, where we both made presentations and talked about our papers afterwards. He criticized mine, I remember, for being too harsh in its judgment of the opinion of Chief Justice Taft in Olmstead v. United States. ${ }^{1}$ This was an authoritarian and rigid opinion towards which he was in no way naturally inclined; yet his capacity for sympathetic understanding led him to see in this unexpected place if not merit or virtue at least humanity struggling with its own limits.

This essay, which is dedicated to him, is about language, one of his

$\dagger$ Hart Wright Professor of Law, Professor of English, and Adjunct Professor of Classical Studies, The University of Michigan. I wish to thank Rudolf Arnheim, Terence Ball, Alton Becker, Lee Bollinger, Kenneth DeWoskin, Thomas Eisele, Paul Friedrich, Lemuel Johnson, Bruce Mannheim, Terrance Sandalow, Frederick Schauer, Domna Stanton, Joseph Vining, and Christina Whitman for their very helpful comments on an earlier draft.

1. 277 U.S. 438,455 (1928). 


\section{Thinking About Our Language}

interests as well as my own. It is intended to assert the value and primacy of what I call literary discourse over a certain kind of academic language, and in doing so to suggest a possibility for more fully integrated and living speech, in the law and elsewhere. In it I set forth a view of language, and its relation both to the individual mind and to the community, that underlies my own investigation of law as a system of meaning, as a culture at once literary and political, and I do so with the hope that it may also be of use to others similarly occupied. While I am sure Bob would have had much to criticize in it, I also like to think that he would have found its basic thrust congenial.

In a famous passage Thucydides says that during the wave of civil wars that followed the Corcyrean revolution words themselves lost their meaning. In the Crawley translation the passage reads as follows:

Words had to change their ordinary meaning and to take that which was now given them. Reckless audacity came to be considered the courage of a loyal ally; prudent hesitation, specious cowardice; moderation was held to be a cloak for unmanliness; ability to see all sides of a question inaptness to act on any. Frantic violence became the attribute of manliness; cautious plotting, a justifiable means of selfdefence. The advocate of extreme measures was always trustworthy; his opponent a man to be suspected. . . Oaths of reconciliation, being only proffered on either side to meet an immediate difficulty, only held good so long as no other weapon was at hand; but when opportunity offered, he who first ventured to seize it and to take his enemy off his guard, thought this perfidious vengeance sweeter than an open one, since, considerations of safety apart, success by treachery won him the palm of superior intelligence. . . . [T]he moderate part of the citizens perished between the two, either for not joining in the quarrel, or because envy would not suffer them to escape. ${ }^{2}$

Here Thucydides talks about social collapse in terms that will seem all too familiar to us-think of Lebanon, for example-but what is most interesting to me is that he focuses attention on a verbal or linguistic deterioration that he finds associated with the social and political one. He does not claim that the shift in language causes the change in behavior; on the other hand, for him that shift does reflect a change in culture that makes certain kinds of speech and conduct-those we associate with civilized life-increasingly impossible.

For me this passage is a kind of emblem, defining a topic and sug-

2. Thucydides, The Peloponnesian War 189-91 (Crawley trans. 1951). 
gesting a view of life that directs attention to the relation between language, on the one hand, and both the individual self and collective life on the other. Without attempting to argue for them here, I shall begin by sketching out some views about the nature of language that suggest the importance of rendering our languages and their uses self-conscious, so that we may criticize them; I shall then, in a spirit of experiment, try to make conscious, and to criticize, that part of our own language that is centered on the word "concept" and its cognates.

\section{RECIPROCITY}

The essential feature of human life exemplified in the passage from Thucydides is the structural reciprocity between language and the individual character (or what we call personality or identity): Each of us is partly made by our language, which gives us the categories in which we perceive the world and which form our motives; but we are not simply that, for we are users and makers of our language too; and in remaking our language we contribute to the remaking of our characters and lives, for good or ill. This remaking is necessarily a shared or collective process, for language itself is socially constructed. The reciprocity I speak of thus exists at the collective as well as at the individual level, for our community is defined by our language-our language is the set of shared expectations and common terms that enable us to think of ourselves as a "we"-and that language too can be transformed.

This implies that on some occasions at least we may be able to contribute to the remaking of our shared resources of meaning, and thus of our public or communal lives. This is obviously the case with great artists and thinkers-their work changes the terms in which we think and talk, the ways in which we imagine and constitute ourselves-and upon reflection we can see a similar process at work in ordinary life as well, as we make and remake our own languages in our written and oral conversations with one another. Language, and the world it constitutes, are thus forever changing-"moderate prudence" loses its force as an appeal and thus as a socially validated possibility - and we change with them, both as individuals and as communities. The ineradicable flux of language, and of the world, so recently "discovered" and lamented by the modernist who learns at last that the language and methods of science are after all not good for all forms of thought and life, is actually structural to human experience, a condition of life that has been addressed again and again by our predecessors. What is required to face this circumstance is not a science in the usual sense but an art-the art of reconstituting language, self, and community under conditions of ontological relativism, an art that is literary 
and rhetorical in character and of which we ourselves are the most important subject.

But what kind of art is this and where can we learn it? Here my own answer has been to turn to our predecessors and betters, to see what they have done. How do Homer and Thucydides, how do Swift and Jane Austen, how do Burke and the framers of the Constitution, address the circumstance I have described, that language constantly changes meaning and that we change too? If words lose their meaning, they also get new meanings, and what is the art by which that is done and done well?

In reading and rereading these and other texts with such questions in mind, while writing When Words Lose Their Meaning, I gradually worked out-in fact largely learned from these texts-what I call a "way of reading," which I could then bring back to them in an organized way. This way of reading proceeds by focusing attention on three places: (1) On the nature of the language a particular writer or speaker has inherited-the language that gives her some things to say and do with words and denies her others, the language that constitutes her natural and social world and gives it meaning. (This is a species of cultural and rhetorical analysis.) (2) On the way he or she acts upon this language, for good or ill, modifying its central terms, or reducing it to cliche, enriching or impoverishing it. (This is a species of literary analysis.) And (3), in a different dimension, on the nature of the social and ethical relations that the writer establishes with his reader, with the people he speaks about, and with the natural world. This can range from the relationship of two that is implied in the making of any text to a set of relationships that creates a whole world: Burke's attempt to create a constitution in his text that will be a constitution for Great Britain-a way of talking that defines a community and its relation to nature-is one example; our own Constitution and certain public and legal texts made under it are others. (Here the analysis is ethical and political.)

From this point of view, the law offers an especially interesting form of life, for at its central moment, the legal hearing, it works by testing one version of its language against another, one way of telling a story and thinking about it against another, and by then making a self-conscious choice between them. It is an institution that remakes its own language and it does this under conditions of regularity and publicity that render the process subject to scrutiny of an extraordinary kind. As an ethical or political matter, the structure of the legal process entails remarkable possibilities-little enough realized in the event-for thinking about and achieving that simultaneous affirmation of self and recognition of other that many (I among them) think is the essential ethical task of a discoursing and differing humanity. These ethical possibilities arise from the 
fact that the premises of the legal hearing commit it to a momentary equality among its speakers and to the recognition that all ways of talking, including its own, may be subject to criticism and change.

The larger public world provides a less formally structured version of the same process, for language and politics work reciprocally, each changing the other, with no dominant partner. I do not think, that is, that one sphere of life, say the economic or the intellectual, determines all the others; thus I think that there is no privileged ground of analysis upon which we can stand, no privileged subject by explaining which we can explain -or ought to try to explain-everything else. The student of politics and society must thus face at the official and collective level exactly the same reciprocity that exists in the relation between the individual self and its culture more generally. We are always making ourselves, as individuals and communities, always making our language; yet we are always being made by our language, by our past, and by the actions of others, and the line between the making and the made is never clear. This means, among other things, that our own habits of mind, of perception, and of feeling are contingent and changeable; they are thus a central part of our proper subject, and this is true for us not only as citizens, or cultural actors more generally, but in our professional lives, as lawyers and teachers and writers. Our work cannot claim to be the kind of science that assumes a validity beyond culture, beyond language, but should hope to be a literary or rhetorical art, a way of working with and within our language.

Once one looks to the languages in which community and character are constituted, one suddenly sees that political and social analysis involves the understanding of a whole set of things not normally thought to belong to it: language, mind, and the reciprocal relation between them; the way language is made and changed, by individuals and by communities; and the way language resists change. To think about language, especially about language change, is to require attention to the processes of speaking and reading more generally, to composition and interpretation. This in turn brings into our field of concern the nature of the ethical and political relations that are appropriate to people who conceive of themselves as language-users and language-makers.

Talking about "politics" itself thus becomes a species of what it describes: How ought we to talk in our own performances? About those performances? These questions invite us to be self-reflective, to make our own processes of thought and speech the subject of our critical attention-for whatever we claim to believe about others must also be true for us. They invite us to resist the fallacies of reductionist theories that can on their own terms account for everything in the world but themselves. 
This means that as we talk about politics or law we shall be taking positions, implicitly or explicitly, on certain large questions about the nature of language and its relation both to culture and to the individual self. To ask, "What are the proper expectations to bring to the political and linguistic activities of others?" is to ask also, "What are the proper expectations to bring to what we ourselves say and do?"

\section{The Language of Concepts}

I want to start to work out a line of response to that question by thinking of some of the implications of the word "concept" (and its cognates) especially as it is used in thought and writing about language and politics. I choose this word because it is a central term in our discourse, and one that for most people seems to be completely unproblematic, a perfectly natural way to talk. But for me it is problematic in the extreme: It has overtones and implications that I find difficult, and it is these difficulties that I wish to explain.

A.

In what follows I shall describe two rather extreme types or models of thought, the "conceptual" and the "linguistic" (or "literary") and I shall argue for the latter and against the former. These will be somewhat caricatured positions-you may even think I am attacking a straw man-but I think it may be useful to pursue them nonetheless. I should say at the outset that the position I mean to support is not the traditional "middle view," but the extreme position on the linguistic end, or what might be called a literary-rhetorical view of intellectual and cultural life.

Although I focus attention on what I see to be the dangers of the word "concept" it is not my object to eliminate the term from our language but rather to identify certain assumptions about language and life that are often associated with its use-assumptions that I think false or misleading, but that can exist, I hasten to add, without its help, and that can also be at least partly denied or resisted by one who uses the term with appropriate qualifications. I seek to use this word, that is, as a way into certain larger qualities of our culture, certain habits of our own minds that are so firmly fixed that they may easily seem to inhere in the nature of thought itself. $^{3}$

In talking about this word and its associations I speak simply as a local informant about my own language, without any claims to knowledge beyond those of my reader, whose language it also is. I do not ask that what

3. Other terms could afford similar access to this region of our culture and of our minds: the word "theory," for example, or "problem" or "knowledge" or "reason" or even "fact." 
I say be taken on faith or authority, but that it be checked against the reader's own experience; and I speak out of the recognition not only that my account of my language may be wrong but that even if it is right it may not, indeed will not, wholly correspond with the experience of another, for there is a sense in which all of our languages are different, none of them identical.

I begin, then, with a statement of my own experience of our language, and I recognize that it has something of the character of an admission: the admission that as I have read articles, mainly in journals of law and philosophy, but in other fields too, that use the word "concept"- the concept of law, the concept of right, the concept of equality-I have found myself repeatedly saying that I simply do not know what this word means. I keep wishing that the writer would use another word-like "word"-or just drop the term entirely. As I say, I do not think that the word "concept" and all its derivatives should be driven from the language. "Conception" as a word for "understanding"- as in "my conception" of law or legal argument, "my conception" of good teaching-seems to me useful; and I suppose I would use "concept" in mathematics and perhaps some other similar fields, as in the "concept of a triangle," or the "concept of a carburetor." And since it is part of my view that writers remake their languages all the time, there is no reason in principle why "concept" could not be used by one writer or another in a way that is adequately, even beautifully, controlled or qualified.

For all language, not just the language of concepts, has its dangers: All languages threaten to take over the mind and to control its operation, with all this implies for one's feelings, for one's sense of self, and for the possibilities of meaning in one's actions and relations. ${ }^{4}$ The art of all speech, all expression, thus lies in learning to qualify a language while we use it: in finding ways to recognize its omissions, its distortions, its false claims and pretensions, ways to acknowledge other modes of speaking that qualify or undercut it. The art of expression is the art of talking two ways at once: the art of many-voicedness. ${ }^{5}$ So it is with the word "concept": Its more appropriate uses, in science and mathematics say, might remain unchanged, for there perhaps it is properly qualified and controlled by the rest of the relevant discourse; but I think its use in linguistics, law, politics, and so forth should be more fully and explicitly controlled by arts of qualification, including those of irony, ambiguity, and contrast, than is

4. Terms that present similar dangers in the field of literary criticism are such nouns as "symbol," or "meaning," or the verb "represent," or the preposition "about" (as in "this poem is about ...").

5. This view is developed at length in J.B. White, The Legal Imagination (1973) and J.B. White, Heracles' Bow 77-106 (1985). 
now usually the case. I am speaking, then, not of necessities but of tendencies, of the forces a particular mode of speaking seems to generate, the directions it moves us, or what might be called its cultural implications. These are the pressures with which our art must come to terms.

B.

But to say this is to invite the question, What can I mean by the "tendency" of a particular form of speech, or its "moving us" in certain directions? Let us consider as an example the language and culture of contemporary economics. Of course economics is a useful, legitimate, and interesting field of inquiry, but it is also a culture, and a culture shaped in part by the implications of its intellectual and verbal habits. Suppose you decided to study the way wealth is created by exchanges, and for purposes of analysis you posited a set of actors, of equal age and competence, each with some control over the material of the universe-called resources-and you assumed as a fundamental psychological principle an unlimited acquisitiveness on the part of each, and therefore, with respect to the resources, a severe structural scarcity. Suppose further you assumed that each agent was interested in its own welfare only, and thus perceived itself to be in permanent competition with all other agents (except those whom it chose to make the object of what economists call altruism). Next you assumed a medium in which surplus could be accumulated without limit. Then you began to see what flowed from these assumptions and tried to analyze real world events in these terms.

If you actually did this you would find yourself caught in a game, perhaps a fascinating game, testing your capacity to draw certain kinds of logical conclusions from the premises stated, a game with a force and life of its own. You would become a player, an economist; you would inhabit a world with its own values, its own realities, its own rewards. From such simplicity, such complexity! And such fun, too, though for me of rather an empty kind (at least until an attempt was made to connect the economic language and its culture to others). For good or ill, the language and its practices would gradually start to shape the way you saw the world and felt about it, your sense of yourself and of others. You might find yourself, for example, thinking and talking too much as if people really were the objects or calculating machines that economics assumes them to be or accepting "GNP" as a measure of a nation's economic health.

Of course one could claim that the language of economics is a scientific theory and as such wholly value-neutral. An economic theory is a simplified version of reality, meant, as all such theories are, not to be a full picture of anything but to permit the organization of data in simplified forms so that predictions can be made, assumptions tested, and so on. (Not 
to worry, says Milton Friedman, economic theory is merely a filing system, to be proved or falsified by experiment. We don't mean what we say: We speak always in hypotheses. $\left.{ }^{6}\right)$ It is also conceivable that the language and culture of contemporary economics, and the body of knowledge they generate, could be subordinated to another culture, another set of values-say concern for the environment or for the welfare of those who seem least able to help themselves. But to achieve such a subordination is for the economic culture as a whole impossible, and for the individual economist difficult indeed: The premises of the discipline to which she has given herself are inconsistent with the premises of the uses to which she wishes to put what she discovers. In the end, despite its claims to be merely hypothetical, economic theory becomes a culture of its own and can be studied and judged as such. ${ }^{7}$

My present point is not to criticize economics-similar analyses, with similarly distressing conclusions, could be made of the cultures of other disciplines, including literary criticism and law - but to suggest how habits of thought and language have tendencies, pressures of their own, that can perhaps be checked or controlled, but ought certainly be reckoned with: how language has real power over the mind that uses it, even the mind that contributes to its reformulation. The cultural implications of one's language can be addressed, perhaps even overcome; but the tendencies are there, and have a force of their own.

G.

To return to our particular subject, then, we can ask, What are the subcultural implications of the word "concept"? Its first pressure, I think, is to direct attention away from language to something else: to the realm of ideas, to what is in the mind, or to some field of intellectual reality, and in each instance to something that is assumed to exist in a realm apart from language. "Concepts" are not words; they are the internal or intellectual phenomena that words are thought to label, as markers, or towards which words are thought to point. To talk about concepts is thus to take a step in the direction of talking as if words have no force of their own, as if they are transparent or discardable once the idea or concept is apprehended. On this view, in its extreme form, the function of words is either

6. See M. Friedman, The Methodology of Positive Economics, in Essays in Posirive EconomICS 3,7 (1953).

7. My remarks are most true of a particular branch of economics, neoclassical microeconomics of the sort especially associated with Chicago, but I think other forms of contemporary economic thought present their own versions of these difficulties. For elaboration of these points, see White, How Should We Talk About Corporations? The Languages of Economics and of Citizenship, 94 YALE L.J. 1416 (1985); White, Economics and Law: Two Cultures in Tension, 54 TENN. L. REv. (forthcoming 1987). 
to identify external phenomena that can be observed or apprehended without the use of language-that rock, or tree, or person-or to define or clarify concepts, which also exist outside language and beyond culture. ("He has a concept in his mind." Is that statement true or false? Neither: It is dangerous.)

One extreme form of the kind of discourse that talk about concepts invites is what I call theoretical, by which I mean that it is definitional, deductive, and empirical in nature. We define our terms on the assumption that they can be reduced to phrases that could substitute for them; rationality consists in manipulating these definitions either in patterns of deductive coherence or in hypothetically descriptive patterns that will be tested by reference to extralinguistic phenomena, which will in turn establish whether they are true or false. Rational discourse, so conceived, is propositional in character; and knowledge, whether factual or conceptual, is of necessity propositional too. Propositions are what we reason about and reason with. (Hence all the talk in the philosophy journals about $P$ and $\mathrm{P}^{\prime}$.)

This set of assumptions derives from the model of "science" that has so powerfully dominated our intellectual life in this century. But the habit of mind and language that I wish to identify is far deeper in our intellectual culture than the disciplines that explicitly model themselves on science. We see it also when a classicist talks about the Greek "concept" of honor, when an analytic philosopher talks about the "concept" of a right, when an anthropologist talks about the Hopi "concept" of time, when a linguist reduces utterances to propositions that have the "same," ultimately conceptual, meaning to be expressed variously in different languages (or "codes"), when a lawyer talks about the "concept" of freedom of speech, when a sociologist or psychologist represents social or psychological "types" as if they corresponded with reality, when someone establishes a department in "The History of Ideas," or when a teacher of writing praises a text for the clarity with which it "gets its basic concepts across." People may of course resist the implications of their usage-by thinking of conceptual variety or change or instability, for example-but this can be done only against the force of the term itself. ${ }^{8}$

8. Consider the following quotation from a writer I admire, composed as part of an effort that I also admire, namely, to insist that modern philosophy recognize the differences that characterize different cultures and languages:

In fact, of course, moral concepts change as social life changes. I deliberately do not write "because social life changes," for this might suggest that social life is one thing, morality another, and that there is merely an external, contingent causal relationship between them. This is obviously false. Moral concepts are embodied in and are partially constitutive of forms of social life. One key way in which we may identify one form of social life as distinct from another is by identifying differences in moral concepts. So it is an elementary commonplace to

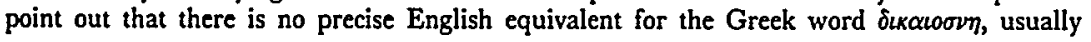


One particular danger presented by such locutions is that we may find ourselves speaking as if there were no reason why people in different cultures cannot have the same concepts, no reason why different languages cannot express the same concepts. To the part of our mind that works this way, indeed, variety of language may come to seem mainly a nuisance, a bother to be eliminated if possible in the interest of what we conceive of as "more efficient communication." For implicit in most talk of this sort is the premise or claim that concepts can be wholly restated, and restated in various languages. Underlying this is the assumption that "communication" occurs not when we speak the same languages-when we understand each other's utterances in the sense that we know how to respond to them, but when we have the same concepts. Although the conceptual world is communicable only through language, it is supposed to exist on a plane above and beyond language, which disappears when its task is done.

While the conceptual view is in principle neutral among languages, and thus would concede that the Chinese translation of our concepts could be as accurate as any statement of our own, in practice it is imperialistic. On this view of language there is no reason why we should learn any other language, any other habits of thought, than our own. At the practical level there is the implied claim that our own language is or can be a metalanguage, in which all propositions can be uttered, all truths stated. And the sense that our language-whether we mean by this English, or economics, or law-is the language into which all others can be translated presents the dangers of linguistic imperialism familiar to us from the ex-

translated justice. And this is not a mere linguistic defect, so that what Greek achieves by a single word English needs a periphrasis to achieve. It is rather that the occurrence of certain concepts in ancient Greek discourse and of others in modern English marks a difference between two forms of social life. To understand a concept, to grasp the meaning of the words which express it, is always at least to learn what the rules are which govern the use of such words and so to grasp the role of the concept in language and social life. This in itself would suggest strongly that different forms of social life will provide different roles for concepts to play. Or at least for some concepts this seems likely to be the case. There certainly are concepts which are unchanging over long periods, and which must be unchanging for one of two reasons. Either they are highly specialized concepts belonging within stable and continuing disciplines, such as geometry; or else they are highly general concepts necessary to any language of any complexity. I have in mind here the family of concepts expressed by such words as and, or, and if. But moral concepts do not fall into either of these two classes.

A. MACINTYRe, A SHORT History of Ethics 1-2 (1966).

Even this writer speaks of "understand[ing] a concept," of "grasp[ing] the meaning of words which express it," and of "rules governing the use of such words." For me these formulations draw attention away from the reality of text and language to another plane, which I think does not exist. I do not think words "express concepts"; I think that utterances or texts made of words have meanings, a rather different thing. I do not think that the use of words is reducible to "rules" (though of course we do have expectations, partly shared, to some degree expressible, which a particular use may confirm or disappoint). Finally, I think that even the key terms in our logic-"if," "and," "or"- - shift from language to language too. Of course the analytic philosopher can insist upon the possibility of translating other locutions into his language, but that is to make exactly the sort of assertion that I think conceptual talk typically makes, and which I oppose. 
perience of many colonial countries-the imposition, say, of English law on the Hindus or the Burmese, or the insistence that all that really needs to be said in Indonesia can be said in Dutch. ${ }^{9}$

Another danger, very widespread in our own world, is that talk about concepts tends to nominalize, and hence to reify, everything. The verb, the adverb, the adjective all give way to the noun. The effect is to create a universe of imagined intellectual objects arranged in quantitative or spatial relations to each other, but without the principle of life that is found in the active verb. Imagine a language that emphasized the verb instead of the noun and copula; our thought would be full of a sense of movement, life, and change, of actors engaged in action.

One who uses the word "concept" in the way I mean, then, is on his way towards making the error of the bureaucrat who can only imagine the world in the terms of his institution; of the Dean who thinks that the merits of any question can be made plain to her in the language of academic planning, without any shift of mind; of the lawyer who thinks that the world comes in legal categories; of the doctor who thinks that the definitions of disease in terms of physical cause and modes of treatment correspond perfectly to the experience of his or her patients; and so on. It is the error of thinking that one's own habits of mind and expression are not to be questioned, that they simply define rationality and coherence. One cannot use a language of concepts, after all, to reflect upon and criticize any of the languages that shape one's mind and world. ${ }^{10}$

D.

Talk about concepts is also intimately, though perhaps not inextricably, tied to dichotomous and linear thinking, to a commitment to a kind of coherence that denies that our terms have shifting and contrasting uses. The most fundamental rule of logic, that of noncontradiction, requires it: Each term in a logical system must be used in such a way that it either is or is not the case that it applies to the world, and, if the system is to be coherent, the word must be used in ways that are at least consistent and preferably identical. This is a struggle for the univocal, for the proposition

9. Consider here Robinson Crusoe's famous account of his relation to the person he found on the island: "II]n a little time I began to speak to him, and teach him to speak to me; and first, I made him know his name should be Friday, which was the day I sav'd his life; . . . I likewise taught him to say Master, and then let him know, that was to be my name . . . " D. DeFoE, RoBinson Crusoe 150 (Everyman's Library ed. 1975) (I owe this reference to Lemuel Johnson.).

10. Of course one can talk about the "concepts" of others with an emphasis on the differences, in an effort to recognize and value another way of thought and life. But $I$ think that to use the term "concept" as a central part of one's vocabulary in such an enterprise is to undercut the enterprise itself, to move oneself and one's reader in the direction of thinking that the concepts exist apart from language and that they can thus be seen by us directly and talked about in our language without loss. 
that is true or false, entailed or not entailed, and it works by propounding questions that must be answered yes or no. This mode of thought is thus not only dichotomous, it is inherently aggressive and defensive, for its claim is to mark out the terrain of truth.

But only one sort of truth. In ordinary language we use our words in richly overlapping, sometimes contrastive ways, and we know that we define our terms partly in the way we use them. The lawyer, for example, can use "jurisdiction," "equity," or "common law" in the most radically different ways without confusion. And, more deeply, poets have always known that life cannot be reduced to systems and schemes. In their poems they often seek to capture assertion and denial at once, to carry the reader to the point where her languages break down. Toleration of ambivalence has long been thought to be an essential ingredient of intellectual, emotional, and political maturity: the capacity to see, with Virgil for example, at once the greatness of Rome and its terrible cost, or with Wallace Stevens at once the fictional character of the poetic world and its reality. The comprising of contrary tendencies, the facing of unresolved tensions, is an essential part of the art of life, as our artists repeatedly teach us. This is one reason why the poem or the drama or the novel, or any other piece of living speech, cannot be adequately represented in a paraphrase, for the paraphrase will normally speak with a single voice, with a confidence of characterization that the poem itself undercuts or qualifies; to the extent that the paraphrase catches the contrasting forces of the poem, its multiplicity of voice and value, the paraphrase approaches the status of a poem itself.

All this is something of a truism as said of poetry, but I think it is true of philosophy too. One of the great vices of much philosophic talk is the assumption that the texts made by Hobbes or Locke, or Plato or Aristotle, can on this point or that be reduced to an outline of an argument. ${ }^{11}$ That of course is not what the writers wrote, but we are terribly tempted-one sees it in student papers and professional essays alike-to reduce intellectual texts to rationalistic outlines. Yet as Plato taught us, and Hobbes certainly knew, all philosophy must in part be about the language in which it is composed, and so too must all law, all history, all linguistics, all criticism. What we know of poetry, that it is not paraphrasable or subject to translation, is true as well of all of our texts, formal and informal. Each speech act has its own meaning. ${ }^{12}$

11. Consider especially the efforts of modern analytic philosophers to translate into propositional and conceptual forms Wittgenstein's Philosophical Investigations, a text that is meant to undermine those very forms. For a good discussion, see Stroud, An End to Anxiety (Book Review), London REV. OF Books July 18, 1985, at 14.

12. This is not to say, with the deconstructionists and other moderns, that there is therefore no meaning, that language "doesn't work," or anything like that. Language has meaning, but not of the 
Under these circumstances the great task is to train the imagination to bring within its field of attention the language through which it functions as well as the non-linguistic world within which it seeks to act. One central difficulty with talk about "concepts" is that it directs attention in just the wrong way, away from language to something that is thought to exist apart from language. And when attention is in fact directed to the problematic character of one particular term, or "concept," as it sometimes is, the rest of the language used is assumed to have perfect stability and soundness. Actually all of our language, not just certain terms within it, is in constant flux. Our use of it, and our talk about it, should alike reflect this fact.

\section{LITERARY LANGUAGE}

But how is this to be done? What view are we to take of language and its meaning?

Let me start with the way in which words mean. For me words are not discrete and definable entities, as much of our talk about them (especially when we are thinking conceptually) seems to assume. They do not carry their meanings like pieces of freight, which the competent reader can pick up perfectly, nor are they reducible to ideas that can be regarded as having some existence beyond or behind language. Any use of language assumes a competence in the audience that the utterance itself does not confer. Much of the meaning of words therefore lies in silence, in the unstated but accepted background against which they have their meaning. Even mathematics is deeply cultural and communal, for its definitions rest on inherently unstable cultural assumptions-e.g., about the meaning of the "shortest distance" in Euclid's famous definition of a straight line. (Can we think of the use of language as teaching one who already knows his or her language how else it may be used?)

What is more, in our actual speech words normally do not exist as units, as I have been assuming and as much of our talk seems necessarily to assume, but as parts of sentences or other expressions, each of which is located in a particular linguistic, intellectual, social and cultural context. ${ }^{13}$ It is not the words themselves but their various uses-or the ways they have been used-that have meaning, and these uses occur in sentences and other gestures that serve the widest range of human purposes. The "pro-

kind implied in most conceptual and analytic talk; it works and works well, but on its own terms, not those of scientific rationalism.

13. For an especially rich statement of the ways in which context gives meaning, see Becker, The Biography of a Sentence: A Burmese Proverb, in TeXt, Play, and Story: The Construction AND Reconstruction of SElf AND Society 136 (E. Bruner ed. 1984) (1983 Proceedings of the American Ethnological Society). 
position," which academics often assume serves as the standard form of thought, is in real speech more rare than one might think. Sentences are perhaps better thought of as "practices" than propositions-including sentences meant to be propositions, for they too exemplify a set of social and rhetorical practices, and do not merely succeed or fail to state the truth. (All this was well known by Samuel Johnson, the great lexicographer, who defined English words not only by substitutive phrases- " $X$ means Y"-but much more richly by their actual and diverse uses in sentences made by eminent writers.) Similarly, the metaphors of a "range of meaning" or a "semantic field," which suggest that words have meanings that can be represented as both two-dimensional and contiguous, like strips of tape or patches of cloth, are utterly misleading, for different uses appear in contexts that are socially, emotionally, and culturally different from each other. It is an abuse of language to try to reduce its meaning to the restatable, the propositional. Our talk about language should reflect the various ways in which it has simultaneous meanings. A better metaphor for the way words mean might be that of neurological ganglia, making up three-dimensional, organic, interactive patterns, which work by processes we know we do not understand, even though they directly coincide, as language also does with our own processes of understanding.

Language has an ineradicably individual character. Words, and other language forms, simply do not mean-not ever-exactly the same things to all users of them, as the builders of intellectual systems must claim or at least hope to achieve. Each of us loads any expression with significances that derive from our prior experience of language and of life, an experience that is obviously different for each of us. And it is not only words that mean differently to different people, but the sentences or other utterances in which they appear, the cultural background against which they acquire their meaning, the silences into which they are intrusions. What is behind the shimmering and fluid world of language is not a world of potentially clear and in principle shareable ideas or understandings, as talk about concepts assumes, but a world of private meanings, radical silences, incommunicable sensations, experiences, and images. Each of us is a circle of experiences and meanings that can occasionally, through language, meet or overlap with others, at least at the edges. Talk about concepts seems to assume that language can be pierced and some underlying reality exposed. I think that cannot be done. What lies beyond language is real all right, but it is not communicable, certainly not in a language of concepts.

I do not mean that meaning is completely private, which would obviously make social and linguistic life impossible, but that for each of us there is always an element or dimension of meaning-perhaps a resid- 
uum, though from our point of view it doesn't feel like it-that is irremediably personal. It could hardly be otherwise when each of us brings to every utterance such widely differing sets of prior experiences, such different aims and wishes. What we call the self is in part the history of a perpetual, and in principle unstable, negotiation between the languageless experience of the organism and its language, a negotiation parallel to those between self and nature, self and other. This history will be different for each of us.

Think here of conversation and life on a law school or college faculty. We can if we are lucky create a world that we can inhabit with confidence and some comfort, upon which we can build much of our lives. Yet despite the sense we sometimes have that the shared world of meanings in such a place is permanent and natural-especially by comparison with such places as Thucydides' Corcyra, torn by civil war-at moments we see that even this world will be maintained only by perpetual and imperfect negotiation. It can always collapse; and at its most healthy much of its meaning is radically different for its different members, and different in ways that never find expression. For one person the school may be a refuge, for another a cosmic challenge; for a devout Catholic the whole process would have meaning of a kind it could not for the atheist; and so on. Part of maintaining a community is maintaining the agreement not to speak or ask about the ways in which its language means differently for different members. And those differences can be so enormous that in listening to the talk one is often surprised that it can go on at all. ${ }^{14}$

I have said that language is more personal or individual than conceptual talk allows, but there is one sense in which it is less so, for conceptual talk assumes that the speaker "has" a concept, indeed must have a concept in order to speak. In fact, of course, we learn our language in large part by imitation, often with a sense only of what is appropriate to specific kinds of occasion. Much of the meaning of what we say is not to be found in our minds or intentions at all, but in the language itself. ${ }^{15} \mathrm{We}$ always say more than we know. This means that learning a language is partly learning from it the meaning of what we already know how to say, which has, without our knowing it, marked our world, our mind. This is why

14. Or think of the formation of a friendship: how wonderful it is to find someone whose language speaks to you, and to whom your language speaks, below the explicit level.

Or think of the task of the lawyer interviewing a client: The story she has just been told makes sense of a kind, no doubt, it may even be compelling and vivid; yet the lawyer never accepts it in its first form but goes on to ask questions the function of which is to make explicit the language behind the language, the context that gives the utterances the meaning they have for the client. She tries to retrieve and make conscious as much of the context as she can in order to discover the range of ways the story can be told, its set of potential meanings.

15. Consider here the meaning of Robinson Crusoe's name, "Master," to "Friday" as he learns it and in the language he is learning. See supra note 9. 
the study of our language is at once a study of ourselves and of our culture.

The difference between conceptual and literary uses of language is especially sharp on the question of definition. As I suggested above, conceptual talk seems to proceed on the assumption that its terms can be stipulatively defined in phrases that could substitute for them, while literary definitions occur in the working of the text itself.

This is of course a commonplace with respect to poetry: We know that the poet creates webs of significance that define one thing in terms of another: the rose in sexual terms, for example, or the spider in theological ones. But the same thing can be seen in texts thought to be intellectual rather than poetic, including legal texts. The good writer knows that she cannot just use the word "privacy" or "foreseeability," for example, as though "everyone knows what it means," and also that a one-line definition will not do. You must give your terms meaning in your use of them, a meaning that will be somewhat different from the meaning that is given them in any other text. ${ }^{16}$ The literary mind thus takes the words and sentences that surround it in the culture as defining incomplete possibilities for expression and action, ways of locating the self and the audience in relation to the culture; it then uses them in ways that transform them, for good or ill, in the relation that the text creates with its reader.

Let me call upon an example here, and one familiar to lawyers. Think of the first sentence of Federalist No. 1, which reads: "After an unequivocal experience of the inefficacy of the subsisting federal government, you are called upon to deliberate on a new Constitution for the United States of America."17 The central word in that sentence is "deliberate," for this is what the text "calls upon" its reader to do; and for another reason too, since this invitation is also a promise, a promise that the text will participate in the deliberation, and do so in such a way as to exemplify its proper form. To this much at least the text is committed.

How is "deliberate" defined? Never by explicit description or distinction, never conceptually or stipulatively. The text does not say, for example, "by deliberation we mean the serious and sustained application of open-minded attention," or something equally thrilling, and then go on to use the term as if it automatically meant what the text declared it to mean. Instead, the term is given meaning by a kind of performance or enactment. This begins, indeed, in this opening sentence, where we learn, perhaps disconcertingly, that "deliberate" does not mean open-mindedness on all topics, as we might be inclined to think, but in this instance takes as

16. More extended discussion of this point in connection with particular texts can be found in J.B. White, When Words Lose Their Meaning (1984), in particular id. at 153-60, 217-19.

17. The Federalist No. 1, at 33 (A. Hamilton) (C. Rossiter ed. 1961). 
a given that the existing government is "inefficacious." Even more, the text is willing to bury that assumption in a subordinate clause, almost as if hoping that the reader, in a hurry to reach the main subject, verb, and object, will slide over it without objecting. We are at once invited to "deliberate" and thrown off balance by the evident commitment of the writer on the question in issue.

But is this so bad? Just because we are undecided does not mean that everyone need be; indeed have we not something to learn from those whose opinions are settled, so long as they are put before us in a candid way? As the writer will say towards the end of the paper, "I frankly acknowledge to you my convictions, and I will freely lay before you the reasons on which they are founded." described below, we have come to see the existence of "conviction" in our interlocutor not as a deliberative vice but as a virtue, as a benefit to us; and perhaps we have come to see as well that a similar state of conviction-based on "reasons"-is what we should aspire to ourselves.

Back to the beginning: In the first paragraph the writer tells us that what will be decided by this process of deliberation is "whether societies of men are really capable or not of establishing good government from reflection and choice, or whether they are forever destined to depend for their political constitutions on accident and force."19 Whatever "deliberation" is, then, it is of the gravest importance; it is opposed to "accident and force," and it involves "reflection," or as he soon says, a "judicious estimate of our true interests, unperplexed and unbiased by considerations not connected with the public good."20

But such "reflection" is most difficult indeed, for the nature of mankind is against it: most obviously because the conduct of those selfishly opposed to the Constitution, who will resist it for reasons of interest or passion, and not fairly participate in debate. ${ }^{21}$ This the writer starts to say, but then corrects himself: many of the opponents are motivated by "upright intentions," 22 though perhaps subject to "honest errors", ${ }^{23}$ more than that, in fact, for there are often "wise and good men on the wrong as well as on the right side of questions of the first magnitude to society"24 and "we are not always sure that those who advocate the truth are influenced by purer principles than their antagonists." ${ }^{25}$ The fault is on both sides. The result

\footnotetext{
18. Id. at 36 .

19. Id. at 33 .

20. Id.

21. Id. at $33-34$

22. Id. at 34 .

23. Id.

24. Id.

25. Id.
} 
will be that a "torrent of angry and malignant passions will be let loose." ${ }^{26}$ We can expect both sides to seek to persuade "by the loudness of their declamations and by the bitterness of their invectives."27

The writer is here imagining a world in which the reader, like other citizens, will necessarily be confused: good men and bad on both sides of the question, everyone out of intellectual and rhetorical control, speakers proceeding by "declamation" and "invective," and so on. This set of circumstances gives rise to the felt need for something else, for what the text calls deliberation-for what it promises to offer us-and in doing so begins to give it meaning. In this context of uncertainty it is a real virtue for the voice of The Federalist to speak out of "conviction." Only the voice of this text, committed to the point of bias but self-corrective too, and utterly candid about its commitments, has the stability and maturity required to think its way through the questions before it. Thank heavens, the reader is led to say, someone knows his own mind, and is willing to speak in such a way as to assist our own "deliberation," and to do so by explaining his "reasons," which are offered to us for our acceptance or rejection on the merits.

This is only the beginning of what could be said on this subject about Federalist No. 1, let alone about the Papers as a whole, one central achievement of which is to work out an extended definition by performance of "deliberation" and "reason" alike, but perhaps it suggests how such an analysis might proceed. And I might add one final point: In defining the conditions of deliberation, of its own utterance, The Federalist describes a discursive world dominated by selfishness, passion, shortsightedness, manipulativeness, and so on. This is just the conception of human nature upon which it ultimately rests the need for the national government, just the ground upon which it resists the republicans, who believe in the possibility of civic virtue. In accepting it as the condition of deliberation the reader is likely to be accepting it in deeper ways as well. The terms upon which The Federalist offers itself, that is, as a place and occasion for "reasoned" talk, distanced from the confusion and irrationality of ordinary life, are precisely the terms upon which it offers the Constitution. Both create the possibility of a new kind of community, based upon a new kind of conversation, of which one central term is "deliberation," as defined in this text.

\footnotetext{
26. Id. at 35 .
}

27. Id. 


\section{Translation}

What I think is called for in our talk about our common life and language, then, is not conceptual talk but what I call a literary discourse, by which I mean language uses that are self-conscious of the limits-of the over-commitments, of the dead spots-in the language itself. ${ }^{28}$

Because concepts are abstract, and because in this paper I oppose the "literary" to the "conceptual," it might be thought that for me literary language has to be concrete or particular. But a resolutely particular language would in its own way be as bad as a conceptual one, at least if it assumed the perfect adequacy of its terms and categories. Instead, what I call literary texts are characteristically marked by a tension between languages, between the concrete and the abstract, say, or between a language of nature and one of morality; the effect is to qualify each language while using it. Their art lies in writing two ways at once. In this respect law is naturally literary, for the legal case as we normally think of it can be neither an exercise in abstract analysis nor the presentation of mere particulars, but requires the interaction of both modes of discourse.

The modern philosopher's question is, "What proposition are you advancing?" Mine is, "What text are you making?" I mean this question to reach the language used, its particular formulation, its relation to its context, the voice of the speaker, his or her definition of audience, and so on. "Who are you in this text, who am I, and what kind of conversation do you seek to establish between us?"

All of this has consequences for one's view of human reason, and for the expectations and standards that one should bring to texts that purport to be "rational," including the present one. Rationality is not the manipulation or explication of ideas or concepts, assumed to have some extralinguistic reality and force, but using words well in accordance with the conditions of reality, including: the limits of language and of our own minds; the reality and contingency of the convictions out of which we function; and the silence that bounds everything we say. Reason, on this view, is not reductive or schematic but integrative: saying what we know to be true in light of all else we know to be true at the same time. (This is the opposite of the view of social science as a filing system.)

This view has consequences for ethics as well. I spoke earlier of the ontological relativism of my view, and while that characterization is accurate enough it does not entail what is usually meant by moral relativism,

28. It is possible to have literary uses of what seem to be nonliterary languages, even, as I suggested earlier, of conceptual languages. It is the attitude towards one's language, as that shows up in one's use of it, not the level of one's diction, that counts most deeply. My opposition in this paper is not to abstract words-after all I use such terms as "conceptual" and "literary" myself-but to certain ways of talking about, and using, such terms. 
for I do not mean to suggest that we are left without a ground of judgment or conviction. Quite the reverse: It is a claim that we can ground our "intellectual" discourse in our actual convictions, in what we "think" conceived of much more fully than we reveal in our analytic and theoretical discourse; and an appeal for a language of morality that is self-consciously moral, of politics that is political, and so on.

Literary use of language, in fact, has an active ethical significance, for to acknowledge the limits of one's own mind and language is necessarily to acknowledge the existence of the other person as well as of other possible languages. The norm for conceptual talk, indeed for much academic talk more generally, seems to be inherently aggressive: The idea is to stake out certain intellectual terrain with the force of one's logic, or by the demonstration of certain facts, against an audience assumed to be hostile, which will be persuaded only if compelled. The literary method, on the other hand, knows that nothing can be said with certain truth or validity, that no one can be compelled to submit, and that compelled submission is worthless anyway. It proceeds instead on the assumption that our categories and terms are perpetually losing and acquiring meaning, that they mean differently to different people and in different texts. It is not a territorial claim but an invitation to reflection. The implied standards for one's own expressions are thus authenticity, actuality, integration, a commitment to acknowledging the limits both of language and of mind. Concerning others a complementary ethic emerges with similar clarity and simplicity: respect for the other (grounded in a simultaneous recognition of similarity of situation and otherness of experience); allowing the other what we claim for ourselves, the authentic assertion of conviction and judgment; and a willingness to learn the other's language and to undergo the changes we know that will entail. What we ask from others is what we offer to them, a willingness to speak to them as they are actually situated and constituted, with recognition of their claims to a language and a world. The heart of this set of ethical practices is the art of simultaneous affirmation of oneself and recognition of the other.

The tendency of much abstract theoretical and conceptual talk is to appeal to the part of ourselves that wants to be surrounded by linear arguments, always hypothetical and susceptible to summarization in logical outline; that wants to live without the personal or actual voice, and without the responsibility of conviction, in a world reduced to quantitative metaphors; that wants to render the world into certain abstract intellectual forms or claim it to be meaningless. It works by an ideal of the purely 
rational where "rational" is given a special and rather bloodless significance. $^{29}$

A proper language of reason, by contrast, a proper language of justice, would accept the literary condition on which we live: that while we struggle for coherence in our expression, this coherence will always be tentative, always incomplete, for all that we say, all that we are, is in part a function of the context in which we live, always imperfectly perceived and always changing. As an example of literary discourse one can think not only of poetry but of law, which has survived as well as it has-and has been as important as it has-because it is a discourse constantly in the process of its own transformation, not in part but all at once, in which speakers recognize that their central terms must be defined anew as they are used in new contexts, and in which all speakers recognize that everything is in principle arguable.

At any given point in time, and place in culture, certain appeals have force-people will listen, feel they must respond, and so on-while certain others do not. As time goes on these appeals, and the contexts from which they arise, shift and grow or wither. (Think for example of the different force of an appeal to the Gospels in the discourse of Harvard University made 100 years ago and today.) This is not merely a matter of intellectual or conceptual, but of cultural change. We can understand much of what the words we translate as "honor" mean in the Iliad, or the plays of Corneille, or what "honor" itself once meant in England, or in South Carolina, yet in our world these words cannot mean what they once did. The English word "honor," which once expressed the motives for which people would kill each other, or go to voluntary death, has now lost much of its meaning; this loss is not merely, or primarily, a "conceptual" one but a loss of force and significance, a difference in relation to the unstated backgrounds and to the feelings of the speakers. Who today would ever ground a conviction on "honor"? This is really the point of the famous passage in Thucydides: A resource is gone, and gone forever, except perhaps as it can be revived or recreated by individual speakers, exercising the kind of art that Thucydides himself, other great writers, and perhaps our best judges too, can be seen to practice.

In our own thought and writing about the texts, practices, and cultures

29. Our own language of moral and political philosophy in particular seems to me badly impoverished. The attempt to convert moral and political distinctions into conceptual ones, expressions of conviction into intellectual points, and to make these choices "rational" in the computational sense that is now so natural to us, is to strip our central terms of much of their force and meaning and to destroy a cultural resource of great importance. 
of others-and our own, too-we should be aware, then, not only of the reality but of the insurmountability of the differences between languages. This means that we cannot simply construct versions of other people's central terms as if we could understand them perfectly. As with other translations, we have to recognize that the most we can attain is an imperfect understanding and approximation. What is called for is not an attempt to penetrate the other world at the level of idea, behind or beyond language, but the effort to learn the language ourselves, incomplete as that learning must of necessity be. ${ }^{30}$

But, you may say, does this not mean the end of all attempts to generalize-to describe, count, weigh-and of all efforts to analyze the real worlds of different cultures, or the different stages of our own culture? $\mathrm{My}$ answer is both yes and no. I do think that it would mean the end of all attempts to treat political or cultural questions as if they were language-free-it would mean the end of pure behaviorism and of the sort of view of individual and collective life that characterizes economics, at least in its unqualified form. But this does not mean that we can say nothing, describe nothing, about these important matters. We can give descriptive, analytic, and comparative accounts of the rhetorical and cultural situations of others; we can study and analyze their responses, creative or not, to their situations as we understand them. We can learn to see and judge their own reconstitutions of their own languages. We can, that is, describe with some accuracy the rhetorical facts (the claims that can and cannot be made); and the literary facts (the ways in which individual speakers and writers remake their languages, for good or ill); and this will go far towards defining the essential ethical and political facts, the ways a particular community is constituted, in a text and in the world. We can identify the appeals and topics that characterize a particular world, and the way they are and can be elaborated. We can do in short what Thucydides has shown us how to do.

But this will not take the form of propositions about concepts or other parts of the nonlinguistic world, which can be elaborated and tested by deduction and induction; nor shall we assume that we can penetrate the minds and languages of others further than we in fact can do. An impor-

30. One's main aim in learning languages-French or Burmese, say-should not be to discover how one can say this or that in French or Burmese, but to learn what one can say and be in those languages that one cannot in one's own. Think of your own first thoughts about learning a language: How different everything would be if you were to greet your neighbor, or your teacher, in French, or order a beer in German, or ask about the weather in Spanish. As sophisticated people we are likely to feel superior to such youthful and romantic expectations, but here, as often, the young and ingenuous have something we should pay attention to. Or think of grammar: Is this the blueprint by which the language is built, the engineer's design document? Much language-teaching seems to assume so, but of course nothing could be further from the truth. Grammar is what we use when we do not have enough experience of a language to make it our own. 
tant part of our attention must always be given to our own language, to its preconceptions and its omissions. This is in a sense nothing new, for it has long been said that one of the points of all comparative studies is to make our own world accessible and criticizable in a new way. My point is that this truth is obscured by those aspects of our current discourse that assume that reality can be authoritatively described and understood in our language, whether on the theory that "material" reality can be described as well by "us" as by "them," or on the theory that nonmaterial reality can be represented and understood as concepts that can be translated without loss into any language.

For me the beginning of wisdom-This is what Plato teaches, for example-is to train the mind to be conscious of its formulations just as it is conscious of the intentions it seeks to realize through them, to be as aware of the language we use as we are of the world in which we use it. What stage of intellectual and ethical development such an awareness, properly disciplined and encouraged, might lead to is beyond our full imagining, but it could be as great a shift as the acquisition of language itself has been. What will lead us to it is not further conceptual elaboration, nor an insistence on the transparency of our own languages, nor the delight in meaninglessness-in the loss of one kind of meaning, that is-celebrated by the priests of deconstruction, but an art, slow to develop, of recognizing the other, an art of assertion within acknowledged limits-an art for which the best word, properly used to reflect its impossibilities, may be "translation." 
